\title{
Sobre un trabajo de campo entre afrodescendientes de Casanare (Colombia): una entrevista con Valentina Villegas Arias*
}

On fieldwork among Afro-descendants of Casanare (Colombia): an interview with Valentina Villegas Arias

RESUMEN

El artículo presenta una entrevista realizada en 2006 con Valentina Villegas Arias, antropóloga colombiana ya fallecida que a comienzos de la década del 2000 hizo trabajo de campo entre una organización de afrocolombianos de Casanare (Colombia). Las respuestas de Valentina ponen sobre la mesa algunos temas que son de especial interés para los antropólogos, tales como el acceso al terreno, los primeros contactos, la delimitación del problema de investigación, el proceso de recolección de datos, el establecimiento de relaciones con algunas personas, la evitación de otras, el trabajo de campo y sus significados personales, y algunas problemáticas sensibles y aún actuales en la sociedad colombiana como el racismo, la discriminación, la marginalidad, las formas de diferenciación cultural, la explotación laboral, el papel de actores armados ilegales en el control social y en las formas de contratación laboral, la reivindicación de derechos culturales y territoriales de los grupos étnicos, las dinámicas de las identidades culturales y los procesos políticos organizativos, entre otros. Además de dejar testimonio escrito de una voz que no está más entre nosotros, el principal objetivo de esta
David E. Arias-Marín

Magíster en Estudios hispánicos de la Universidad de Montreal. Candidato a PhD en Literatura de la Universidad de Montreal.

$\square$ de.arias.marin@umontreal.ca (1) ORCID: 0000-0002-8043-3281 जi Google Scholar

* Antropóloga de la Universidad Nacional de Colombia. 
entrevista es reflexionar sobre las implicaciones de hacer antropología en Colombia, lo que el trabajo de campo significa para algunos de sus practicantes y la visión que desde su formación profesional ofrecen estos de los problemas del país y de sus grupos étnicos.

Palabras clave: trabajo de campo, antropología, Valentina Villegas, afrocolombianos, Casanare.

\begin{abstract}
The article presents an interview conducted in 2006 with Valentina Villegas Arias, a diceased Colombian anthropologist who in the early 2000s carried out fieldwork among an Afro-Colombian organization in Casanare (Colombia). Valentina's responses lay on the table some topics of special interest for anthropologists such as access to the field, first contacts, the delimitation of the research problem, the process of data collection, the establishment of relationships with some people, the avoidance of others, fieldwork and its personal meanings as well as some current issues in Colombian society as racism, discrimination, marginalization, forms of cultural differentiation, labor exploitation, the role of illegal armed actors in social control and in the forms of labor engagement, the struggle for gaining cultural and territorial rights, the dynamics of cultural identities and organizational political processes. In addition to leaving a written testimony of a voice which is no longer between us, the main objective of this interview is to reflect on the implications of doing anthropology in Colombia, what fieldwork means for some of its practitioners and the vision they can provide from their professional background about the problems of the country and its ethnic groups.
\end{abstract}

Keywords: fieldwork, anthropology, Valentina Villegas, Afro-Colombian, Casanare.

\title{
Introducción
}

E ntre los años 2005 y 2006 me di a la tarea de recoger algunas historias sobre el trabajo de campo antropológico. Estas historias, ya un poco olvidadas entre la bruma del tiempo y el olvido, contienen información valiosa sobre las condiciones en que los antropólogos llevan a cabo sus investigaciones sobre el terreno en diferentes contextos de Colombia y las realidades de los grupos que estudian. 
Mi labor consistió en contactar a los antropólogos (con algunos de los cuales compartí espacio en las aulas universitarias), concertar entrevistas con ellos, entrevistarlos, transcribir nuestras conversaciones y después editarlas para incluirlas en un documento titulado "Ser otro por un momento: diez relatos sobre el trabajo de campo antropológico" (2007), el cual, a la postre, se convirtió en mi trabajo de grado de maestría en antropología. En dicho documento mi principal objetivo no era teorizar sobre el trabajo de campo de los antropólogos ni poner estos textos en diálogo con aparatos conceptuales sobre el mismo tema. Mi propósito era más bien registrar las voces de una decena de antropólogos para ayudar a construir unas narrativas personales por medio de las cuales pudieran responder a la pregunta sobre lo que el trabajo de campo en cuanto experiencia iniciática había significado para cada uno de estos.

Las personas entrevistadas eran en ese momento antropólogos y antropólogas recién egresados de antropología de la Universidad Nacional de Colombia o estudiantes a punto de concluir sus estudios de pregrado en la misma universidad. Todos ellos provenían de la academia y gozaban para ese entonces de algo que algunos añoran después de alcanzar la fama: la tranquilidad que brinda el anonimato. En ese entonces la mayoría de ellos tenían entre 25 y 26 años (excepto uno, que tenía 35). Desde entonces han transcurrido cerca de tres lustros y hoy me pregunto, con ocasión de este artículo: ¿qué habrá sido de sus vidas?

Hace algún tiempo, me informaron, precisamente, de la muerte intempestiva de una de las antropólogas entrevistadas: Valentina Villegas Arias, destacada estudiante y egresada de la carrera de antropología de la Universidad Nacional de Colombia, sede Bogotá, quien trabajó durante un periodo de su vida entre comunidades afrodescendientes de Villanueva, Casanare (Colombia). Entre la producción académica de Valentina Villegas se destaca "Los planes de vida: un arma de doble filo" (2008), artículo en el que la autora reflexiona sobre el carácter ambiguo y problemático de los planes de vida y los potenciales beneficios y perjuicios que estos traen a las comunidades que participan en su elaboración.

Puede decirse, de alguna manera, esta entrevista con Valentina forma parte de una tendencia autorreflexiva de la antropología que se abrió paso desde los años 60 del siglo pasado con la publicación de algunos volúmenes sobre el trabajo de campo antropológico. Se trata de una corriente en la que, coincidiendo con la aparición de movimientos feministas en diferentes lugares del mundo, los testimonios de las antropólogas destacaron, ya que por medio de ellos estas se posicionaron como narradoras y protagonistas de sus relatos, contando y reflexionado sobre 
sus vivencias en el terreno y las implicaciones de género en sus trabajos de campo (Powdermaker, 1966; Golde, 1970; Beteille y Madan, 1975; Mead, 1975; De Laguna, 1977; Cesara, 1982; Smith y Kornblum, 1989; Catell y Schweitzer, 2006; Robben y Sluka, 2012; Benedict, 2017; Gmelch y Bohn Gmelch 2018, por citar solo algunos ejemplos). Cabe decir, sin embargo, que a pesar de esta similitud, los contextos de investigación son diferentes, y los relatos fueron producidos en condiciones distintas, ya que mientras en los trabajos citados las autoras las mismas autoras se encargaron de plasmar por escrito sus experiencias, en este caso el texto surge de un contexto oral de conversación semiestructurada que se dio entre la antropóloga y el entrevistador.

En ese sentido, el rol que asumí es el mismo que se espera y exige muchas veces de un antropólogo: el de un mediador o facilitador que, en virtud de su intervención, hace posible que ciertas cosas funcionen mejor, "se dinamicen" (como señala la misma Valentina más abajo) o salgan a la luz. En efecto, traté de crear las condiciones, y sobre todo la confianza, para hacer que las narrativas personales sobre el trabajo de campo de los antropólogos fueran contadas de una manera espontánea y no demasiado académica. A este respecto, debo decir que tuve la suerte de contar con excelentes interlocutores con los que, aparte de establecer charlas amenas e interesantes, hicieron posible que la transcripción y edición de los relatos resultara una labor bastante placentera. Quisiera pensar que esta clase de textos podrían ser algún día leídos no solamente por antropólogos, sino por un público más amplio que por alguna razón u otra se interesa en cuestiones antropológicas. Es por ello que en lo que sigue los lectores no encontrarán un artículo académico en el sentido convencional del término, sino una entrevista que, dadas las condiciones de producción, respeta algunas de las características propias de las interacciones orales.

Quiero insistir en los alcances del artículo, los cuales, hay que decirlo, no se refieren únicamente a las consideraciones que hace Valentina alrededor del trabajo de campo. Desde mi perspectiva, uno de sus mayores aportes tiene que ver con la comprensión que desde su óptica de antropóloga tiene acerca de las realidades y problemáticas que afectan a las comunidades que estudia (y que en buena parte siguen sin ser resueltas) y que determinan las condiciones de vida y laborales no solo de los afrocolombianos, sino también de campesinos y de otros trabajadores rurales de Colombia. El actual contexto político y social del país justifica una relectura de esta conversación con Valentina y sirve como excusa para una reflexión sobre los avances y retrocesos en materia de derechos sociales, culturales y laborales de 
los grupos étnicos de Colombia, de los trabajadores en general y de sus procesos organizativos.

\section{Contexto de la entrevista}

Traté por primera vez a Valentina Villegas en cuarto semestre de la carrera de antropología, cuando ambos tomamos el curso de Taller de técnicas etnográficas. Si me remito a su aspecto físico, la recuerdo como una persona de estatura mediana (1,65 metros aproximadamente), de cabello crespo y largo de color negro. Usaba lentes pequeños y redondos y vestía con frecuencia sandalias y pantalones anchos de rayas y multicolores. A veces, cuando nos cruzábamos en los pasillos del edificio de aulas de Ciencias Humanas, hablábamos un poco sobre los cursos que en ese momento tomábamos y sus respectivos profesores. De andar ágil y ligero, me pareció siempre una persona descomplicada, de aquellas con las que podía hablarse de lo que fuera sin temor de ser juzgado. Siempre supe que era muy buena estudiante, ya que, de hecho, obtenía unas notas altísimas en los cursos.

A Valentina dejé de verla durante un tiempo, hasta que un día, por casualidad, la encontré de nuevo en algún recodo de la universidad. Esa vez me contó sobre su viaje de seis meses a Europa y su estadía en los Países Bajos, de donde acababa de regresar para emplearse en un proyecto de investigación en Bogotá. Puesto que por ese tiempo yo andaba en busca de interlocutores para mi trabajo de maestría, propuse a Valentina realizar una entrevista con el fin de que me hablara un poco sobre alguna de sus experiencias de trabajo de campo en el Casanare. Ella accedió sin problema y el resultado de aquel encuentro es lo que aparece a continuación: una conversación sostenida entre el humo de sus cigarrillos y el aroma del tinto con panela que esa tarde me ofreció en su apartamento del centro de Bogotá.

\section{D.A. ¿Cómo llegaste al Casanare? ¿Cómo fue tu primer acercamiento?}

V.V. Yo empecé a ir al Casanare en el curso de Laboratorio de investigación, el cual tomé con Myriam Jimeno en el primer semestre del año 2000. Estábamos con todo el cuento de formular el proyecto de grado, y formulando el proyecto de grado yo quería mirar los efectos de la política multicultural del Estado. Tenía un poco de ejemplos que quería explorar así, a vuelo de pájaro. Quería mirar y profundizar un poco la información a través de entrevistas a gente que conociera, que hubiera trabajado específicamente esos problemas. Me acordaba mucho de una situación que nos contó (Luis Guillermo) Vasco acerca de una muestra aquí en Bogotá. Una muestra en la que combinaban grupos de rock y de teatro con rituales 
indígenas. Empezaron con un ritual indígena. El ritual, yo no me acuerdo de qué comunidad era, pero el ritual era de tres días. Claro, cuando ya el ritual llevaba dos horas y la gente estaba mamada ${ }^{1}$, los encargados de la organización del evento empezaron a sacarlos, y ellos dijeron: "A nosotros nos invitaron a hacer esto y nosotros lo vamos a hacer". Y ellos aquí en una tarima, y por el otro lado los organizadores siguieron con la programación cultural. Eso fue lo que nos contó Vasco. Tenía ese ejemplo.

D.A. ¿Cómo llegaste al terreno? ¿Cuáles fueron tus contactos? ¿Qué dificultades encontraste?

V.V. Tenía una compañera trabajando en Casanare la influencia de las representaciones de identidad en la migración de la gente negra al Casanare. Y tenía otros más. Entonces Myriam (Jimeno) me insistió en que tenía que aterrizar la pregunta en alguno de esos problemas porque si no, no iba a hacer nada. Y me dijo que me fuera para Villanueva, que era de las pocas del laboratorio que estaba pensando en trabajo de campo y que tenía la posibilidad. A mí me sonó y yo le pregunté a Sara, mi compañera, qué opinaba de yo irme para allá. En esa época existía una tensa calma. Ya los paras estaban instalados, tenían su rollo y llevaban mucho rato ahí, y ahí la situación es que se ejerce el control de la población: quién entra, quién sale, qué está haciendo, pero digamos que es calmado. Todo el mundo está constreñido en lo que puede o no puede hacer, qué es lo que puede pasar en el pueblo o qué pasa si hace tal cosa, pero no había enfrentamientos, o los enfrentamientos eran por allá con la guerrilla en el Meta.

D.A. ¿Cómo definiste tu problema de investigación?

V.V. Yo aterricé mi problema de investigación ahí. Hice el proyecto y me fui para allá. En esa época, el proyecto se llamaba Negriauncas: tensiones y negociaciones para no sé qué cosa...

\section{D.A. ¿ Negriauncas?}

V.V. Sí, Negriauncas, porque ese era el nombre del grupo con el que yo iba a trabajar, que se llamaba Negritudes Asociados Unidos por el Casanare. Entonces era eso: Tensiones y negociaciones como para... como proyecto de aplicación de la Ley 70... no me acuerdo cómo era bien el título. Eso después obviamente se cambió, porque ya el choque en campo me mostró más o menos cómo era el problema del asunto, qué era lo que debía tener en cuenta. 
D.A. Entonces te fuiste a Villanueva con ese proyecto en mente...

V.V. Sí, yo viajé a Villanueva con Sara. Ella me llevó, me presentó la gente. Inicialmente me presentó una muy buena amiga de ella, que en ese momento era la secretaria de esa organización, y a su familia. Me presentó más gente de la asociación. Ellos eran todos miembros fundadores o en ese momento miembros de la junta directiva...

D.A. Perdón te interrumpo... ¿Tienes idea de cuántos negros hay ahí en Casanare?

V.V. La cifra de negros en el Casanare siempre varía, porque ellos tienen una estrategia de supervivencia, que es que ellos se mueven por "mallas". La población flotante, se le dice, se mueve por "mallas". Donde sale trabajo para hacer infraestructura, para sembrar, allá van. Se van por periodos de tiempo. Entonces es difícil hacer un cálculo. Supuestamente la organización calculaba que había unas mil personas. Alcanzamos a contar setecientas, pero sabíamos, las mismas familias nos decían: "Aquí también vive un hermano que está trabajando en Aguazul en arroz". Ese era como el cuento. Pero hubo muchísima gente en el momento en que empezaron los "enganches"3 de gente negra. Por ahí hay testimonios que tenemos que decían que había hasta cinco mil personas.

D.A. Entonces es difícil hacer el cálculo. Pero bueno, me decías entonces que fuiste con la gente de la organización...

V.V. Sí. Yo conocí a los miembros fundadores y de la junta directiva, pero yo ni siquiera sabía cómo les iba a plantear el proyecto. No lo tenía muy preparado y una noche llegamos a una casa y ahí estaban Erwin M., Raúl R. y Ricardo O, que son miembros fundadores. Sara es muy amiga de ellos, me presentó y les dijo: "Ella les trae una propuesta para hacerles". Yo les dije qué era lo que me interesaba ver, que era ver cómo era el proceso de organización, qué dificultades habían tenido en el camino, cuáles eran sus metas, quiénes estaban, qué hacían, cómo era todo ese proceso. Yo decía: “¿cómo les pinto a ellos que esto les sirva?". Además de hacerles énfasis en la posibilidad de hacer una reflexión del proceso que llevaban, les dije que había llevado cosas que creía que de pronto les podían servir.

\footnotetext{
Redes de personas que se mueven en función de una actividad económica temporal. Para mayor explicación, ver la p. 122, último párrafo.

Se refiere a una forma de contratación colectiva de diez o más trabajadores que son trasladados de una región a otra para trabajar.
} 


\section{D.A. ¿Qué hiciste entonces? ¿Cómo recibieron tu propuesta?}

V.V. Me conseguí toda la legislación sobre ley de tierras, sobre etnoeducación afrocolombiana, hablé con gente del $\mathrm{PCN}^{4}$, me enteré como en qué iba el proceso de organización de gente negra a nivel nacional, los grupos, cuáles eran las posiciones, qué hacían, como para poder situarme en esos contactos, como para que ellos pudieran conocer qué se movía aquí. Y yo creía que eso podía ser de interés para ellos de acuerdo con lo que me había contado Sara que eran sus intereses. Ya de ahí, esa semana pasaron varias cosas que me permitieron situarme en una forma muy cercana en lo que fue las personas con las que trabajé, porque mientras recorría el pueblo iba conociendo las oficinas, y Sara me presentaba un poco de gente que me podía servir en la alcaldía, en la emisora, gente de las juntas de acción comunal. Me daba el legado de todas esas relaciones.

D.A. Mencionaste antes a los paramilitares y el control que ejercían sobre la zona. ¿Cómo fue tu entrada al campo?

V.V. Alguna vez fuimos a un ensayo del grupo de danzas que tenía la asociación. Ahí estuvimos con los "chinos" y jugamos. Estuvo bien la cosa. Bailamos un poquito. Eso fue como un jueves, y el sábado ellos tenían una presentación, porque era el cierre de campaña de Uribe y la celebración del Día del Niño. Entonces fueron dos cosas que se movieron paralelas en el pueblo y que reunían a toda Villanueva. Ese día era el hormiguero en el pueblo. Nosotros nos fuimos para lo de la presentación de los "chinos" y estando en la presentación, había un poco de comparsas de niños, niños disfrazados. Ese día me golpeó mucho, me impactaron mucho varias cosas: por un lado, antes de empezar la presentación, había un desfile de esas comparsas. Y los niños en sí como son de crueles, pero entonces los niños no negros señalaban a los niños negros. Les decían: "¡Ay, mire ese negrito!". Ver esos comportamientos me impactó. No pensé que hubiera situaciones que fueran tan chocantes, en términos de un problema racial, por decirlo así. Fuera de eso, llegamos a la presentación, los "chinos" se presentaron, la persona que presentó el grupo me pareció muy curioso lo que dijo, porque el tipo cuando presentó, dijo: "bueno, vamos a ver el grupo de Negriauncas. Ellos son una colonia caucana que hay aquí, porque, aunque ustedes no lo crean, aquí también hay negros". Y para mí sobraba un comentario que, siendo ese un evento local, entre los vecinos, porque finalmente era eso, pues que dijera "aunque ustedes no lo crean", sabiendo 
que los negros llevan 20 años. En ese momento usted dice: "bueno, aquí pasan cosas!".

D.A. Pues claro...

V.V. El caso es que se dieron las presentaciones, se presentaron los "chinos" y a la gente le gustó muchísimo, porque obviamente los "chinos" pa' bailar son unos berracos. Son un grupo entre 8 y 13 años. Y al final: "no, que bailen otra, que bailen otra". Nosotros habíamos ensayado una danza con ellos, y pues no había más "chinos" y el presidente me dijo: "¡Quítese las chanclas y salga allá a bailar!", y yo me fui a bailar con los "chinos". Entonces, como ahí estaban todos los papás y la Alcaldía y todo, fue una entrada que después me abrió a mí muchas puertas. Al otro día hubo una jornada cívico militar de la Alcaldía. Pero antes hubo otra cosa que me impactó de esa entrada a campo esa primera semana. Saliendo de ese evento, los "chinos" se fueron a cambiar donde habían dejado la ropa. Y les gritaban vainas por la calle, cosas racistas. Hubo un pedazo que pasamos por una zona donde hay talleres de mecánica, y pasó un man así con las manos engrasadas y cogió un niño de unos ocho o nueve años, el man se limpió las manos de grasa, se las pasó por todo el pecho y la espalda... ¡se limpió en el "chino"! Y todo el mundo, "bueno, qué”. Y uno reacciona, pero pues también sabe dónde está reaccionando y pues...

\section{D.A. Claro...}

V.V. (...) Al otro día hubo una jornada cívico militar de la Alcaldía. La noche anterior un man de la Junta de Acción Comunal había buscado al presidente de Negriauncas a decirle: "Oiga, ustedes no nos metieron en ninguna de las actividades de mañana, no están para las listas de atención médica ni están para las listas de mercado, ni nada". Entonces que por qué no mandaban una persona temprano para que estuviera ahí en lo de la organización y bregara a pasar una lista. Bueno, por cosas terminamos Sara y yo, que éramos las que íbamos a hacer eso, realmente terminé yo ahí. Eso terminé de recreacionista, de todo, y eso me permitió entrar muy bien en términos de lo que usted me preguntaba de los paramilitares. Porque a la semana siguiente, a la organización le habían prestado por la tarde el computador de la Asociación de Juntas de Acción Comunal para trabajar. Se los prestaban porque estaban conmigo y pues yo sabía manejar el computador. Entonces nos lo prestaban por la tarde que no funcionaba y allá llegaron a preguntarme: "Que qué está haciendo, nosotros la hemos visto". Fue un señor solo. Y no, "eso está muy bien", dijo él. Digamos que eso tuvo sus ventajas. Eso fue la entrada a campo: cómo entré, quién me entró y a dónde llegué. 
D.A. Ya. Entonces bueno: llegaste al campo, accediste a la organización y a algunas personas. Ya sobre el terreno, ¿cómo enfocaste tu proyecto?

V.V. Yo tenía muy en la cabeza como que la Ley 70 influía en lo que pasaba en Villanueva. La Ley 70 es la Ley de Negritudes o de Comunidades Negras. Digamos que tiene varias características principales: define una noción de comunidad negra específica que está anclada en lo que son las comunidades de la Costa Pacífica. A esas formas de organización, de economía, de propiedad de la tierra, de toda la parte cultural que se maneja allá, se circunscriben unas manifestaciones culturales específicas que las definen. Definen esos criterios que permiten reconocer a una comunidad negra, y como le digo, con la imagen de las comunidades chocoanas, que a su vez también tienen un análisis muy cercano a lo que son las comunidades indígenas de allá. Eso lo define, por un lado. Por el otro, también define lo que son los territorios. Lo que dice la Ley 70 es que se van a legalizar las propiedades colectivas de las comunidades negras de allá, con base en lo que son los sitios de apropiación del territorio que ellos manejan, lo que han ocupado ancestralmente, en fin, todo ese cuento.

\section{D.A. Entiendo, claro...}

V.V. La otra definición que es importante ahí es la de "comunidades ribereñas". Resaltan su relación con la naturaleza, su forma de economía que es más limitada a la subsistencia y lo que eso implica en términos de impacto al medio ambiente, de conservación de la diversidad, y bueno: montan todo ese discurso. Pero entonces, todo lo que son las comunidades y las poblaciones negras que viven en ciudades grandes como Bogotá, Cali, o en ciudades intermedias (que podría de pronto Villanueva incluirse ahí...), en fin, otras personas que tengan prácticas culturales diferentes a esas, ¿dónde quedan? Por ejemplo, los costeños quedan por fuera de eso. Sin embargo, digamos que los análisis que uno lee en general acerca de lo que ha sido el movimiento de la población negra, meten mucho la Ley 70 como un motor que cohesiona, que permite organizarse.

\section{D.A. Y esa ley, en Villanueva, ¿cómo se aplicaba?}

V.V. En Villanueva no tenían ni idea de qué era la Ley 70. No. Mejor dicho, llegaron a que yo les contara. Y yo pues puede que me la hubiera leído, pero cuando una ley pasa de los términos en los que uno la lee a su aplicación y a que se traduzca en prácticas concretas, en oficinas, en una acción, en comprar una tierra, en una partida, ya pues que sepa uno eso cómo se hace, es otra cosa. Y fuera de eso, pues como sabe que está circunscrita para la gente negra del Pacífico, pues finalmente personas como, 
digamos las de Villanueva, lo que hacen es cogerla y apropiar una cosa que no se aplica para ellos. Como discurso, que es como la usan, les puede servir, porque es la ley de negritudes y lo justifican mostrando la piel. Pero que sean las personas que están definidas como objeto, como sujeto de ley, en esa ley no es así. Fuera de eso, Negriauncas era el resultado de una división de un proceso organizativo que ya llevaba un tiempito en el Casanare.

\section{D.A. ¿Cómo así?}

V.V. Qué pasa: que una de las estrategias para instalarse y apropiarse del territorio de la población negra ha sido la organización. La organización ha estado ahí en diferentes momentos, adoptando... cómo le digo yo... yo no sé si eso se podría decir que... se apega a identidades específicas. Pero, en fin: lo cierto es que hubo sindicato. La primera organización negra es una organización comunitaria. Adopta la figura de organización comunitaria, que eso lo promueve la gobernación del Casanare, que es para tramitar esos proyectos de vivienda social allá en el Casanare para autoconstrucción y por el financiamiento y todas esas cosas. Paralelamente, ya empiezan a conocer qué es lo que está pasando con la Ley 70, pero finalmente son ciertas identidades las que se están moviendo...

D.A. Se da una especie de articulación entre identidades y organizaciones...

V.V. Algo así. Pero qué pasa: cuando la gente negra migra al Casanare, migra inicialmente por "enganches". Las empresas palmeras cogen un bus y lo mandan allá con una persona que representa a la empresa. Lo mandan al Cauca. ¿Por qué al Cauca? Por varias razones: porque allá estaba la caña y era un cultivo agroindustrial y entonces eso situaba a la gente que participaba en la caña como técnicos en el cultivo. Ya conocían cómo era el cuento. Fuera de eso, la caña estaba en crisis, o sea que había mucha mano de obra disponible. Pero eso además tiene el rollo de saber de quién eran esas tierras. Y fuera de eso, estaba, desde el siglo XIX, el planteamiento de la gente que había pensado el desarrollo del Casanare. Esta gente había dicho: "No, es que allá no entran sino los negros". Por los estereotipos que hay de su fortaleza, de todas esas cosas que están sustentando los estereotipos raciales, entonces todo eso lo sacan: que son fuertes, que resisten el calor, que eso mejor dicho trabajan hartísimo, que es como si no se cansaran, que no sé qué... pero es que eso también, pues mire: ¿finalmente a dónde los meten?

D.A. Sí, claro... me imagino que viste y oíste muchas cosas en relación con eso... 
V.V. Los testimonios de la gente son impresionantes en términos de lo que ellos encontraron: esas selvas, llegar a desmontar monte de sabana, ese monte que se hace allá que es pesado, culebras, cosas a las que la gente supuestamente piensa que ellos están acostumbrados, iy pues no! Finalmente lo hacían como una necesidad económica. Entonces esta gente que llega -en "enganches" llegan sobre todo hombres jóvenes y solos y desempleados- el "enganche" activa la red: "No, este se fue, por allá está bueno". O el que se vino se trajo los amigos. Hay gente que se encontró en el camino. Que había gente trabajando por allá en Buenaventura y después terminó por allá. Otra gente que ya estaba migrando por allá por Mitú y terminan allá. Eso activa todas esas relaciones. Y ellos llegan allá y qué pasa: la misma gente que vive en Villanueva dice que Casanare es muy racista. Y yo no lo limitaría ahí. Hubo de verdad un encuentro ahí fuerte con lo que eran los prejuicios. Fuera de eso, competencia en la mano de obra. Hombres solos, competencia por mujeres. ¡No, eso era...! Se desataban muchos conflictos con la llegada de ellos allá.

D.A. Claro. Hay unos temas de identidad ahí implicados. ¿Tienen ahí en el Casanare algo así como una identidad o un estereotipo de lo que significa ser del Casanare?

V.V. Es difícil definir al casanareño. El argumento que yo presento finalmente es que ahorita, en términos de presentar una identidad casanareña, la identidad casanareña no la define solamente el nacer ahí. Ahí hay mucha gente. Precisamente por lo que significa el Casanare y la Orinoquia en general, la imagen es la "tierra de promisión". Allá se puede hacer de todo. Ese es el polo de desarrollo del siglo XXI y no sé qué, y eso crea movimientos poblacionales detrás de ese sueño. La identidad y ese sentimiento de territorialidad se construyen en relación con eso. Y en una tierra de promisión, usted sabe, no hay cuna. Las posibilidades de ser y de proyectarse son ilimitadas, son de acuerdo con lo que usted sea. Ese es el imaginario que se mueve. Pero realmente la tierra de promisión también tiene sus constricciones y sus estructuras, y allí se reprodujeron las mismas de donde vienen los migrantes.

D.A. Ya. Pero, entonces no viste una reivindicación de identidad muy definida para la gente de ahí, al menos ahí en el contexto donde estuviste...

V.V. El casanareño, por ejemplo, un criollo del puro llano, es una combinación entre cimarrones de Venezuela, porque allá hubo una población negra del siglo dieciséis y todo eso (que sobre eso no se ha profundizado), y el criollo es una combinación. Hay criollos que, en cuanto a color de piel, 
son renegros. Pero usted no puede llegar y darle a entender a él (al criollo) que lo está equiparando a un negro del Cauca...

D.A. ¿No?

V.V. No, porque se pone bravo. Y, por ejemplo, ellos combinan muchas cosas de la cultura indígena. La curación a través de rezos, muchos seres de la naturaleza allá toman otro nombre, pero son los mismos. Yo creo que el supuesto casanareño que ellos quieren reivindicar y al que se aferran así es el que está asociado al trabajo de llano, a la vaquería, a todo eso que se maneja y que está ligado a esa actividad económica en específico.

D.A. En medio de ese panorama, ¿qué pasó entonces con tu proyecto? ¿Seguiste con el mismo tema o fuiste cambiando a medida que ibas encontrando cosas?

V.V. Desplacé el centro de atención de mi etnografía: me centré en las redes. Me centré en lo que finalmente le daba cuerpo a eso. Yo tomé dos cosas: una, lo que eran las motivaciones, qué era lo que quería la gente. ¿Por qué la gente estaba ahí? Y otra, el contexto que favorecía que esa organización se viera como se veía.

D.A. Ya. Lo has mencionado antes, ¿pero cómo es eso de las redes? ¿Cómo funcionan ahí en Villanueva?

V.V. Los trabajadores que llegaron al Casanare se ubicaron de dos maneras: unos en galpones, en campamentos. Y hubo trabajadores que llegaron con sus familias, porque obviamente los trabajadores, puede que muchos hayan llegado a ocupar las mismas posiciones en la empresa, pero hubo otros que llegaron de una vez como supervisores porque ya eran supervisores allá, de plantación. Y hubo gente que estando ahí, y que llegó a hacer lo que hizo todo el mundo, a tumbar monte, a asperjar abono, a sembrar y a abrir todo eso, allá tuvo oportunidades y escaló posiciones dentro de la empresa. Creció socialmente en comparación a como llegó. Y eso finalmente también juega mucho ahí. Entonces esas personas tuvieron la oportunidad, tuvieron casa en la plantación. Como tenían una mayor estabilidad económica, lograron traer a su familia. Otros se casaron con las mujeres de allá.

D.A. ¿Ah, sí? 
V.V. Sí, claro. Por ejemplo, hubo una cosa muy bacana que sucedió dentro de esas luchas de apropiación territorial, que es que los empleados, los trabajadores del palmar, empezaron a hacer huelga por la comida, porque las cocineras eran boyacenses. Eran de ahí de la región, y ellos querían pescado, patacón, toda la vaina, y dándoles chocolate con pan. ¡Eso era impensable! Entonces ellos decidieron, la empresa después de cambiar de cocineras, decidió decir: "No. Hay que traer mujeres negras". Y ellos empezaron a llamar a las primas, a las novias, y entonces ellas empezaron a trabajar como aseadoras, como cocineras, les arreglaban la ropa a los ingenieros. Y fuera de eso, hay muchas mujeres que en este momento son las administradoras del casino, que es el restaurante. Porque eso, en términos del proceso de diferenciación, allá también es significativo. Entonces son muchas cosas: es como una apropiación que se ve en muchos sentidos. Por ejemplo, los fines de semana ellos salían de la plantación y se tomaban el pueblo. Y fuera de eso, ellos eran los que más consumían, eran los que tenían finalmente el dinero en ese momento. En ese momento, con respecto a los trabajadores agrícolas del resto de la región, ellos eran los que ganaban más. Entonces se activaba el comercio, ellos llegaban y ¡cuál joropo! Llegaban con salsa y les tenían que poner salsa porque ellos eran los que iban a consumir, mal que bien. Es todo ese juego. Y apropian zonas. Hay bares. Cuentan por ejemplo que había bares en donde no entraba negro, y había bares en donde no entraba blanco. Cosas así. Los conflictos toman otras manifestaciones menos violentas con el tiempo, pero como le dije al principio, cuando yo llegué me encontré de una con que eso existía.

D.A. Quisiera volver un momento a la presencia de grupos armados en esa zona, particularmente de los paramilitares, que son los que están ahí donde estuviste. ¿Cómo lo ves tú? Has hablado un poco de cómo eso incidió en tu trabajo de campo, ¿pero podrías ampliar un poco más eso y sobre la relación que estos grupos tienen con organizaciones del tipo de la que investigaste?

V.V. Lo de los paramilitares yo no sabría cómo caracterizarlo, porque eso es como por épocas. Qué pasa: los paramilitares se quedaron allá para controlar un sindicato que crearon los negros. En el 86 hubo una organización de un sindicato, de lo cual allá no se puede hablar. Yo logré conseguir alguna información al respecto, pero no es un tema del que la gente suela hablar con facilidad. La empresa había firmado un pacto colectivo con los trabajadores. A través de ese pacto algunos accedían a préstamos y todo, pero los reclamos de ellos finalmente eran para garantizar esa estabilidad que permitiera apropiarse de Villanueva (es decir, construir casas). Y eso iba condicionado por la posición que la gente tuviera dentro de la empresa. En esa época, Puertos de Colombia se desbarajusta. 
Y usted sabe que ese era uno de los sindicatos más fuertes. Dicen que gente de allá llegó al Casanare y los empezó a asesorar para que se conformaran como sindicato. Hay muchos testimonios que muestran que eso era legítimo porque la empresa realmente tenía un manejo complicado de lo que eran los accidentes de trabajo, el manejo de los contratos, la liquidación, el trato mismo en la plantación. Había cosas ahí raras.

Yo tengo muchos testimonios de gente a la que echaron sin motivo, que se enfermó y no le respondieron, cosas así. Armaron, pues, severo sindicato, pero resulta que la gente no firmaba el sindicato porque el sindicato todavía no tenía personería jurídica. Donde los pillaban, los jodían. Y antecitos de que les dieran la personería jurídica, la situación fue la siguiente: había uno de la junta directiva del sindicato que tenía un hermano, y ese hermano era muy cercano a una persona de un cargo importante ahí dentro de la empresa, el superintendente. Entonces el man le contó, a pesar de eso, de que estaba jodiendo a su misma gente, pero le interesaba quedar bien con el patrón. Y lo escogieron y entonces empezaron presiones, los trasladaron. Finalmente, eso no terminó en nada y les desarticularon todo y eso se lo atribuyen a los negros. Se refieren a ellos en términos del comportamiento de su independencia. Ese fue el primer intento de organización que hubo allá. ¿Qué pasó después de eso? Allá explícitamente lo dicen: las palmeras los trajeron para controlar. Y eso fue también una cosa que permitió ejercer la otra parte de la presión, que generó dos cosas: por un lado, que la gente firmara el pacto colectivo, que se sometiera a las condiciones que les ponía la empresa. Y la otra, "se abrieron". Se fueron, además porque quedaron con el estigma del sindicalista, entonces ahí ya no conseguían trabajo. Yo creo que ahí toma mucha más fuerza esa red que yo digo que es como regional, que se consolidan realmente esos sistemas de malleo (ver explicación más abajo), porque antes finalmente había mucha gente que sí tenía unas condiciones estables de trabajo. Pero ahora sí, con la flexibilización de las condiciones laborales, usted no se imagina la cantidad de gente que se mueve a través de trabajos temporales por todo el Casanare. La movilidad es impresionante. Se llaman "sistemas de malla" porque son redes que se mueven con esos puntos o esas actividades productivas que salen en una época determinada, pero son contratos de dos o tres meses. Por ejemplo, van a hacer una siembra de arroz. Se llevan un combo. Los echan los cuatro meses que se demore el arroz, o los seis, dependiendo de qué variedad saque, y cuando es la cosecha vuelven y los contratan y los meten en un campamento. O sea, es mucho más fácil que tener una persona sosteniéndola todo ese tiempo sin ser productiva. Eso funciona mucho con petroleras.

D.A. ¿Y después de eso qué pasó? 
V.V. Siguieron varias reestructuraciones en la empresa, y se acabaron los campamentos. Entonces la gente salió del campamento para Villanueva, pero así: con una mano adelante y otra atrás. Entonces ahí cuentan que hubo una época muy tenaz. Además, la presión en Villanueva no es solamente en la población afrocolombiana que estaba trabajando en palmas, sino también alrededor. Hubo mucha migración de gente de diferentes partes del país, entonces había hacinamientos en todas partes. Fue una situación muy crítica. Hay unos escritos muy interesantes de los que eran los administradores en esa época (ya era alcaldía). Cuentan los que han sido los retos de la municipalización, y hablan de eso, de lo que es la presión sobre el espacio. Todas esas cosas de trabajo superan las expectativas de la gente y obviamente las expectativas del municipio, las posibilidades de los municipios para recibirlos en condiciones dignas. Ellos salen, se organizan así más o menos como le digo, en hacinamientos así tenaces, y en el 94 pasa una cosa muy bacana: se organizan en una colonia. En el 91 (me regreso un poquito para que entienda esto de la colonia) crearon la fiesta del pueblo. Entonces era el Festival de las Colonias. Pues como allá hay gente de todas partes, entonces la idea era reunirlos. Los boyacenses tenían su propia fiesta por allá, los llaneros su propia fiesta por allá, entonces lo que hicieron fue reunir todo eso en una sola celebración y que todo se mostrara. Para la tercera versión de ese festival nació la colonia caucana. La propuesta fue de una señora que allá es muy importante, muy significativa en todo lo que ha sido el proceso de organización, que se llama Zaira O. Ella es de Palmira, y ella estaba antes en la colonia del Valle del Cauca. Ella allá manejaba todo lo que era la parte de las comidas. Entonces ella, siendo valluna, propone lo del Cauca. Toda la gente estaba presionando armar su propia colonia porque quienes manejaban las del Valle no eran ellos. Y a pesar de la salsa y lo que sea, y que la comida es súper parecida, había que crear esa otra colonia. Entonces organizaron esa colonia, iy no!, mejor dicho: eso llevaron un grupo de acá de Bogotá que es muy conocido. Llevaron ese grupo y quedaron muy bien parados y con ánimos. Esa colonia la apoyó una persona que en este momento es un político muy importante allá, que es caucano también y es payanés (obviamente no es negro). Él era un ingeniero del palmar y tenía muy buenas relaciones con la población negra. Participaba de las fiestas, jugaba fútbol, esos espacios en ellos que son de reconocimiento y que son tan importantes, y esa participación los hizo muy cercanos y el man los animó. Me imagino que les prestó apoyo económico. Eso nadie lo dice, pero me imagino que ahí debía estar él. Y después de eso el man se iba a lanzar a la alcaldía. Les dijo que sacaran un concejal, y se empezaron a reunir y sacaron a Zaira. Y efectivamente este tipo ganó la alcaldía y Zaira ganó el concejo. Para eso, tenían un grupo de trabajo, el de hacer política, y ese grupo después tomó cuerpo. 
Cuando esta gente salió elegida, pues yo me imagino que la gente como que sintió apoyo y cogieron e invadieron los terrenos del municipio y armaron sus casuchas en un momentico y empezaron todos los concejales a joder, que llevaran militares, que no sé qué, que desalojaran, y el alcalde no desalojó. Él mandó a hacer un estudio socioeconómico y vio que la gente cumplía con las características para entrar en esos programas de vivienda que en ese momento estaban empezando a marchar, tengo entendido, el Fondo Nacional de Vivienda, o algo así. Era un fondo de vivienda nacional que se podía apoyar desde lo departamental. Entonces como era para casa, ahí se organizaron en la organización comunitaria, y cuando Zaira entró a este mundo de la política, conoció a Saúl M. Entonces se las llevaron para el Chocó y ella conoció allá el proceso de organización y ya a esa organización comunitaria le pusieron apellido y se llamó Afrocolombianos de Casanare. Entonces todo fue como paralelo ahí. El man negoció con ellos para que liberaran el terreno. Lo liberaron y desbloqueó y empezaron a construir, y así se consolidaron dos barrios que hay -hay gente no negra ahí, pero mayoritariamente es gente negra la que vive ahí-, que son El Mirador y el Brisas del Upía, que tiene dos etapas, la uno y la dos. Hay gente que salió del palmar y ellos sí habían firmado el pacto colectivo, estaban bien situados dentro de la empresa. Llevaban un buen tiempo ya, como ocho años, y eran supervisores, gente del laboratorio, de maquinaria, cosas así. Ellos tuvieron préstamos y ellos sí armaron sus casas en otros barrios que ya estaban consolidados para esa época. Esa organización sigue y después se divide y ya sale Negriauncas. Esa parte ya tiene más un enfoque en lo productivo, en mirar qué otras alternativas económicas encuentran diferentes a la palma, porque ya las condiciones laborales a ellos les cambiaron totalmente desde que empezaron a ahora que están allá, y en eso se han centrado los otros afrocolombianos del Casanare y Negriauncas, que ahora se llaman Afrouncas.

D.A. Es una historia compleja. Dime una cosa: ¿cuántas veces fuiste al campo?

V.V. Yo hice dos etapas de campo: una del 23 de abril a principios de junio. Me vine a presentar el reporte de laboratorio, a terminar un trabajo que estaba haciendo acá, y en agosto me volví a ir hasta diciembre. Allá me quedaba en la casa de unas personas, que eran tíos de $\mathrm{S}$. El señor se acababa de jubilar y él fue de los que fue a mover tierra en Villanueva cuando lo empezaron a construir, y a él le pagaron con lote. Él se quedó con un lote y empezó a construir su casa y se demoró 20 años construyendo su casa y yo llegué a los tres meses que ellos ya se habían instalado allá. Ahí viví... ¡una casa más buena! Pero esas dos etapas de campo fueron cualitativamente distintas. Como yo inicialmente empecé con Negriauncas, Negriauncas 
también reúne a personas específicas dentro de la comunidad negra. Por ejemplo, a mí sí se me hacía muy curioso que cuando ellos se describían a sí mismos o se hacían alguna identificación, era que ellos eran muy aparte. No todas las personas están dentro de estas características que yo le voy a decir, pero influían mucho en la diferenciación que se hacen entre unos y otros...

\section{D.A. Por ejemplo...}

V.V. Voy a empezar por Mariam P. y su familia. Ellos eran miembros de la asociación. Eran el papá de Mariam con sus hijos, Mariam con su marido y con sus hijos, como dos hermanas más de ella con sus familias, un tío... bueno, un combo. Ellos son chocoanos. He ahí la primera diferencia. La señora es chocoana y -por ponerlo en términos de esas odiosas clasificaciones- una zamba, casada con un bonaverense, y tuvieron sus hijos ya en Villanueva. Entonces eso que fueran chocoanos tenía su ingrediente. Fuera de eso, ellos estaban económicamente mejor que muchas otras personas. Entonces, por ejemplo, don Mesías, el padre de esa casa, él llegó allá manejando maquinaria, y su cuñado era el jefe de personal. Entonces él fue una de las personas a las que la empresa les prestó la plata para que construyera su casa. Él se jubiló allá y entonces pudo montar su taller, y desarrolló una actividad independiente de la palma. Eso allá gratifica socialmente. El marido de Mariam, por ejemplo, tiene vacas. Él llegó a tumbar monte, a asperjar abono y empezó a ganarse a los instructores y entonces se hizo amigo después de un man, le ayudaron a estudiar y estudió una tecnología agropecuaria en el SENA y terminó manejando los animales allá y después, en un recorte de personal, lo sacaron. Pero el man estudió, quedó con su platica y tiene sus vacas y ahorita tiene un negocio distinto.

\section{D.A. Cuando hablas de clasificaciones, ¿̇a qué te refieres?}

V.V. Resulta que hay unas clasificaciones. Las describo: en el Chocó en sí hay un poco de clasificaciones. Quibdó es capital. Una persona de Condoto o una persona de Istmina o algo así, es diferente. Y entre mineros y pescadores también hay diferencia porque el minero tiene más platica. Eso, si lo ponemos en términos de plata. Pero además hay diferencias culturales que entre ellos mismos también genera que la gente se posicione, se quiera diferenciar de los otros. Eso se da de todo. Ahora, en términos de regiones, tenemos Chocó, Cauca y Valle. ¿Qué pasa ahí? En este caso se combina que la gente del Chocó tiene más platica. Y además, entonces, caucanos y vallecaucanos... Ellos describen esa situación de la siguiente forma: en un baldado de cangrejos, el que quiere subir, los otros lo cogen de las patas. Porque prima esa igualdad. En las relaciones tiene que primar la igualdad 
y el que se salga de esa norma, hay diferentes mecanismos sociales con los que lo quieren bajar, ya sea con el chisme, o si puso un negocio, pues todo el mundo va y le fía y no le paga, y todas esas cosas. ¡Y eso funciona! Y yo creo que en un poco de comunidades. Yo no sé si eso tenga que ver con una vaina socioeconómica, pero sí esa filosofía, o yo no sé cómo se podría llamarle a eso. Por ejemplo, entre los indígenas también. Terrible. Y por eso es que salen las rencillas. Todos esos son mecanismos sociales para el mantenimiento de la igualdad, supuestamente. O así están clasificados por la antropología. Lo que le quiero decir es que entre esas dos etapas de campo yo pude acceder a las otras personas y a efectivamente darme cuenta de qué era lo que diferenciaba a algunas de otras, que igual esas fronteras son muy móviles, porque siempre va a depender del contexto. Hay contextos en los que no importa, "somos todos negros y esas diferencias que hay entre nosotros...", supuestamente, para funcionar hacia afuera, "tienen que borrarse". En muchos casos estas personas se querían clasificar como "más juiciosos que...". Mostraban que ellos no participaban en las rumbas, porque allá esos espacios son muy importantes. Entonces cada ocho o quince días había una fiesta en estos barrios que son reconocidamente negros. Y allá eso es una cuadra oyendo música y bailando y comida. Ellos no participan de esos espacios, entonces eso crea diferencias. Son diferentes.

D.A. Entiendo. Una pregunta: ¿conociste primero entonces a Mariam P. y su familia?

V.V. Sí. Inicialmente yo los conocí a ellos. Y efectivamente, durante esa primera etapa de campo, si acaso yo me tomé una cerveza, me la tomé con los señores. Con ellos y ya, pero no en una fiesta. Cuando yo llegué, en la segunda salida de campo, una vez me invitaron a un bazar los de la otra asociación. Mejor dicho, Negriauncas es una división. Cuando yo llegué, para mí solamente existía Negriauncas y ellos me decían que Afrocasanare, la otra organización, ya se había disuelto. Pero resulta que eso no era así. Antecitos de la época, cuando ya iba a empezar así en forma la época de elecciones, esa organización se activó. Y empezaron a reunirse y quien la activó, el presidente, habló conmigo y me dijo que si les ayudaba. Yo le dije: "Pues invíteme a una reunión y miramos qué hacemos". Nunca me invitaron a una reunión finalmente, y una vez me invitaron a un bazar, pero habían quedado de avisarme, y el día que fue el bazar, finalmente yo no me enteré, y me enteré al otro día. Eran como las diez de la mañana y yo iba hacia los barrios de allá. Allá le dicen abajo, porque es la dirección del caño. Yo vivía en El Morichal, que es a todo el lado opuesto. Entonces yo vivía arriba y ellos vivían en la parte de abajo. Yo iba en la dirección del caño (sí tiene algo de ideológico). 
Entonces yo iba pa' allá y me encontré con una señora, doña Lidia. Yo tenía una reunión con alguien, era un domingo, o tenía una entrevista (yo no me acuerdo qué era lo que iba a hacer) y me encontré con doña Lidia. Ella venía con todos los shorros ${ }^{6}$ encima y me dijo que había estado buenísimo ese bazar, que por qué no había ido, y yo, "Ay, no, finalmente no me avisaron, que no sé qué", y me dijo: “¿Sabe qué? Yo la invito a una fiesta. Dentro de ocho días yo voy a cumplir 70 años. Caiga a la casa". Yo: "¿A qué horas le caigo?". Y me dice: "A las seis de la tarde". Yo: "Bueno".

Pues a los ocho días, que era la fiesta, a las seis de la tarde cayó un diluvio llanero pero brutal. Yo salí como a las nueve de la noche. Cuando llegué, apenas estaban organizando (y pues siquiera no llegué más temprano). Entonces cuando yo llegué, primero doña Lidia se quedó mirándome como toda: “AAh!". Estaba sorprendida. Ella no pensó que yo fuera a llegar allá. Eso después me lo dijo. Pero entonces yo pensé que no se acordaba de mí. Yo dije. "No, qué pena tan...". Pero entonces ya me hicieron seguir y me hicieron pasar a la sala, y pues las mujeres todas estaban haciéndose sus trenzas y peinándose y la uña y tal, y los señores trayendo el equipo, otras estaban cocinando allá. Y ya nos sentamos a hacerle visita. Entonces yo llegué y me metí a la cocina y les dije que en qué les podía ayudar. "No, que cómo se va a poner". "No, venga, preste", y me puse a cocinar con ellas. Y entonces me di cuenta de que eso llamó la atención.

\section{D.A. ¿Qué pasó después de la fiesta?}

V.V. Después de esta fiesta, yo conocí muchas más personas. Yo, por ejemplo, tenía la oportunidad de sentarme a hablar con las mujeres de todas las edades y recibía impresiones sobre mí, sobre mí como mujer. Yo tenía entonces 22 años. Entonces, una mujer de 22 años, sin hijos, por allá, y fuera de eso que yo soy de Manizales, que vivo en Bogotá, entonces me decían que chévere, pero les parecía raro. Además, porque yo había dicho que estaba casada, lo que no era cierto. Lo dije para evitar problemas de líos con otros hombres. Y fuera de eso, que yo estaba casada y que cómo mi marido me dejaba estar por allá todo ese tiempo. A mí me tocó en esa época decirle a mi novio: "Oiga, toca venir a hacerme visita porque si no, no me van a creer el cañazo". Entonces ahí por ejemplo recibía esa impresión. Entonces ahí yo me metí a la cocina, les ayudé y después las mujeres de mi edad se me acercaron.

D.A. Claro, gracioso eso. ¿Qué pasó entonces con las mujeres? 
V.V. Un día nos pusimos a hablar. Yo era una de las poquitas solteras que estaba ahí. Estaba sola. Se hacían conmigo porque a mí me traían trago, porque los hombres les ofrecen a las mujeres si están solas. Si no, no, para evitar problemas. Entonces ellas se quedaban ahí conmigo para que les dieran también "chorro". Ese día quedé en unos papeles muy raros: pa' partir la torta, para ayudar en la repartición... como si yo estuviera, como si fuera parte de esa casa y de las personas que ofrecían la fiesta. Listo. De ahí para adelante, yo por donde pasara en esos barrios que me veían por ahí cazando pispirispis ${ }^{8}$, eso me llamaban de la casa, ya como que conocí a las mujeres, más a los jóvenes, ya gente que estaba por fuera de las organizaciones. Ya me di cuenta de que las redes no se limitaban a la parte organizativa, que eso no agotaba toda la cosa. Empecé a darme cuenta. Ellos me decían: "iAy, es que nosotros pensábamos que usted no tomaba aguardientico ni bailaba!". Y yo: “NNo! ¡Cómo!”.

Ahí ya empezó otra dinámica de la cosa. Realmente yo no quería hacer trabajo de campo ahí, pensando en que eso de pronto me podría traer problemas como de celos profesionales con mi compañera. Entonces como que yo no tenía muchas ganas. Pero a mí Myriam era la que me decía: “PPero es que vea! ¡Usted puede hacer trabajo de campo! ¡Mire esta gente (refiriéndose a mis compañeros), quién puede hacer trabajo de campo! ¡Vaya!". Y finalmente pues fue como eso. A mí me interesaba el efecto de esas políticas de la Ley 70 en la realidad social. Entonces, por ejemplo, en ese sentido, yo me estaba armando un cuento como para mirar un poquito más desde la parte económica. Pero era porque yo estaba montada en un rollo, porque ellos estaban detrás de tierras. Sara me contaba más o menos como qué era el proyecto que ellos querían hacer. Yo lo estaba mirando como más por ese lado y eso realmente no existía más que como una idea y un comentario que había salido. Eso era lo primero que me interesaba.

D.A. Ya. Cambiando de tema: ¿por qué estudiaste antropología? ¿Cómo llegaste a esa decisión?

V.V. Realmente me acuerdo de lo que le dije a mi mamá: que yo quería estudiar con gente. Eso fue lo que le dije, o algo así. A mí me gustaba era trabajar con gente. No sé por qué antropología específicamente, pero sí me daba la idea como de trabajar con gente.

D.A. ¿Te ha marcado hacer trabajo de campo? 
V.V. Yo creo que no existe un antropólogo al que no lo marque de alguna forma u otra el trabajo de campo que hace en un sitio específico. Pero recuerdo particularmente un día que me sentí muy mal. Ellos querían hacer una celebración. Estaban bregando a celebrar hacía dos años. Era la conmemoración de los 150 años de la abolición legal de la esclavitud. Eso fue en el 2001. Y en el 2001 ellos habían cuadrado todo y finalmente no lo hicieron. Entonces estaban bregando hacer para el 2002. Y friegue y friegue y friegue, y haga lobby. Ese día pasamos todo el día en la alcaldía sentados afuera esperando. Y cuando salió el alcalde les dijo: "Miren, ¿saben qué? Yo tengo destinados setecientos cincuenta mil pesos para eso y se los voy a dar en el sonido”. ¡Después de que les había dicho que los iba a apoyar con dos millones de pesos! Pero tenían unas expectativas muchísimo más grandes sobre eso y lo que habían preparado para hacerlo ya llevaba trabajito y toda la vaina. Y yo, que como quien dice, no tuve en cuenta toda esa lucha que se llevaba allá, en un momento yo le sugerí al que se había quedado conmigo ahí esperando: "iAh! ¡Mejor dejar eso!”. Y él me dijo: "No. Es que, si lo permitimos, nos van a seguir pasando por encima de nosotros de la misma forma en que siempre pasan". Entonces yo me quedé pensando y dije: "No, sí, tiene razón". Entonces seguimos andando y nos encontramos con doña Nadia. Y doña Nadia se salió de los chiros cuando él le contó, y dijo: "¡Ah, claro! ¡Ahí están pintados en la alcaldía! Ellos creen que...", todo es textual, "iellos creen que porque somos negros y porque somos pobres tenemos que andar pidiéndoles a ellos, pero no!". Entonces, ¡claro! Pues yo hice el recuento de todos los hechos y yo decía: "Claro, les roban de frente y los tratan como si no existieran". Además de lo impotente que se siente y de todo, eso como que me agobió en ese momento y me pegué una chillada. Me sentí mal. Además, porque como yo me moví en toda la parte de la organización, de la vuelta y el lobby, de vamos a hablar con tal, de tin, no sé qué, uno veía una actitud poco favorable al proceso que se llevaba. Entonces jah!

D.A. Claro. ¿Pero te gusta hacer trabajo de campo? ¿Crees que eso te aporta algo a ti como persona?

V.V. A mí me gusta harto hacer trabajo de campo porque, no sé, eso es una cosa que ya han dicho, pero es que uno aprende mucho. Hay retos, hay situaciones en las que uno se ve y lo ponen a prueba a uno como persona en todos los sentidos. Porque es que uno en campo es uno. ¿Sí me entiende? O sea, usted puede que tenga unas redes en las que se puede apoyar para ciertas cosas, pero finalmente es usted con lo que usted tiene ahí y ya. Entonces como que esos retos que le ponen a uno ciertas situaciones me parece que lo hacen a uno crecer. Fuera de eso, es importante el darse cuenta de que entre la realidad empírica y la teoría hay esa posibilidad 
que uno tiene de construir. Es a partir de lo que vive y lo que ve que se construye, no de lo que lee hacia abajo.

D.A. ¿Llevas diario de campo?

Me gusta el diario de campo. Me gusta mucho hacer el diario de campo, sí.

D.A. ¿Crees que llevar un diario y hacer trabajo de campo te confronta?

V.V. Es que uno se ve en situaciones duras. Se ve uno a veces en situaciones que: “¡Jm! ¿Y yo aquí cómo llegué? ¿Cuál es mi papel acá?”. Porque en muchos casos a veces uno tiene que pensar cómo actuar. O sea, no siempre tiene que pensar cómo actuar, pero a veces eso le implica realizar demasiadas cosas de una. Uno tiene una forma de ser y reacciona a ciertas cosas de ciertas formas, pero uno siempre es así. Yo siento que el trabajo de campo me ha cambiado, y si no lo hubiera hecho, mejor dicho, hubiera perdido el tiempo. Aunque yo creo que a ratos como que yo me involucro mucho en el trabajo de campo y eso no siempre es bueno. Ofrece como muchas posibilidades y muchas ventajas en términos de cómo puede uno saborearse lo que está haciendo. Pero a veces lo pone a uno en unos papeles que superan el momento de un trabajo de campo y que, si uno lo ve en las condiciones en las que se desarrolla todo esto, pues finalmente va a quedar como truncado.

D.A. Aparte de investigar, ¿cuál crees tú que es el papel del antropólogo en el campo?

V.V. Cuando pienso en las organizaciones en las que yo he participado, porque finalmente todo mi trabajo ha sido en proceso organizativo, pienso que uno llega a dinamizar una cosa. Porque uno se da cuenta que hace aportes mucho en términos de poder recoger, de poder recoger y mostrar qué hay, más que entender y tener. De decir: "Bueno". Pues sí puede ofrecer caminos y cosas así, pero uno como que puede acelerar ciertos procesos. La sola facilidad que tiene de escribir una idea. La idea está, alguien la dijo, pero escríbala. Ese ejercicio, que igual lo puede hacer cualquier persona, eso marca.

D.A. ¿A qué te refieres?

V.V. Me refiero a que a veces queda uno como en lugares de una responsabilidad que supera lo que uno tenía en la cabeza de hasta dónde podía llegar. Cualquier acción es impredecible. Uno no sabe. Pues eso a veces lo pone a uno en papeles angustiantes, porque se vuelve una madeja de 
relaciones que uno dice: "bueno, qué es lo que está sosteniendo esto y qué es la cantidad de cosas que lo sostienen", y uno dice: "No, hay relaciones que es mejor primero no establecerlas, y segundo, no alimentarlas". Eso es lo peligroso del trabajo de campo, y del trabajo antropológico en general. Pero igual, creo que vale la pena. Y mucho.

D.A. Bueno, Valentina. Muchas gracias, has sido muy generosa con tu tiempo y tu relato.

V.V. No, de nada. Ojalá le sirva.

D.A. Sí, seguro.

\section{Referencias}

Arias Marín, D. (2007). Ser otro por un momento: diez relatos sobre trabajo de campo (tesis de maestría). Universidad Nacional de Colombia, Bogotá, Colombia.

Benedict, R. (2017). An Anthropologist at work. London, UK: Taylor and Francis.

Beteille, A. y Madan, T.N. (eds.) (1975). Encounter and experience: Personal accounts of fieldwork. Honolulu, USA: University of Hawaii Press.

Catell, M.G. y Schweitzer, M.M. (eds.) (2006). Women in Anthropology. Autobiographical narratives and Social History. Walnut Creek, USA: Left Coast Press.

Cesara, M. (1982). Reflections of a woman anthropologist: No hiding place. New York, USA: Academic Press.

De Laguna, F. (1977). Voyage to Greenland: A personal initiation into Anthropology. New York, USA: Norton.

Gmelch, G. y Bohn Gmelch, S. (2018). In the field. Life and work in Cultural Anthropology. Oakland, USA: University of California Press.

Golde, P. (ed.) (1970). Women in the field: Anthropological experiences. Chicago, USA: Aldine.

Mead, M. (1975). Blackberry winter: my earlier years. New York, USA: Pocket Books.

Powdermaker, H. (1966). Stranger and friend: the way of an anthropologist. New York, USA: Norton.

Robben, A.C.G.M. y Sluka, J.A. (eds.) (2012). Ethnographic fieldwork: an anthropological reader. Malden, USA: Wiley-Blackwell and John Wiley \& Sons.

Smith, C.D. y Kornblum, W. (1989). In the Field: Readings on the Field Research Experience. New York; Westport, USA; London, UK: Praeger.

Villegas Arias, V. (2008). El Plan de Vida: un arma de doble filo. Etnias E Política. Revista del Observatorio Indígena de Políticas Públicas de Desarrollo y Derechos Humanos, 9,114-139. 